\title{
Analysis of allergenic residues in wines by triple quadrupole LCMS
}

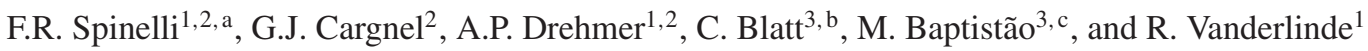 \\ ${ }^{1}$ University of Caxias do Sul, Institute of Biotechnology, Rua Francisco Getúlio Vargas, 1130, 95070-560 Caxias do Sul, RS, Brazil \\ ${ }^{2}$ Brazilian Wine Institute (IBRAVIN) - LAREN/SEAPI - Laboratory of Oenologic Reference Evanir da Silva, Av. da Vindima, \\ 1855 Caxias do Sul, RS, Brazil \\ ${ }^{3}$ Agilent Technologies Brazil, Alameda Araguaia, 1142, Barueri 064555-940, SP Brazil
}

\begin{abstract}
During the winemaking are used technology coadjuvants, between them: albumin, caseinates and lysozyme. These compounds have great oenological properties, however, the presence of their residues can represent risks to people who are allergic to them because they are derived from eggs and milk. Mass spectrometry methods enables unambiguous determination of allergenic proteins at low levels in wines. Therefore, the aim of this study was to determine the concentrations of ovalbumin, alpha-casein, betacasein and lysozyme in experimental wines treated with different concentrations of them by triple quadrupole liquid chromatography mass spectrometry with Jet Stream Electrospray Ionization (ESI). The wines were elaborated and treated with different concentrations of albumin, lysozyme and potassium caseinate. Bentonite and decantation were used for the removal of the fining agents. The quantification limits (LOQ) for ovalbumin, a-casein, b-casein and lysozyme were: $0.002 \mathrm{mg} / \mathrm{L}, 0.24 \mathrm{mg} / \mathrm{L}, 0.75 \mathrm{mg} / \mathrm{L}$ and $0.04 \mathrm{mg} / \mathrm{L}$, respectively. Non residues of the proteins were identified in the experimental wines treated with the different amounts of potassium caseinate, albumin and lysozyme, analyzed in this study. These results provide an evidence of the absence of residues of caseinate, albumin and lysozyme in the concentrations tested in the wines if good treatment practices are followed.
\end{abstract}

\section{Introduction}

In EU Regulation 1308/2013 [1] in combination with OIV-COMEX 502-2012 [2] labeling is mandatory when there is presence of egg or milk residues above the limit $(0.25 \mathrm{mg} / \mathrm{L})$; in addition, according to the Comission Implementing Regulation (EU) $\mathrm{N}^{\circ}$ 579/2012 [3], terms or a pictogram can be used to highlight the presence of allergens.

The OIV adopted in 2014 a Code of good fining practices for wine to be applied in the use of proteinaceous wine fining agents with allergenic potential (casein and egg white) (Resolution OIV-OENO 520-2014) [4], specifying the steps to carry out the clarification and filtration process, avoiding residues of fining agents, with potential allergenic effect, which may be present. Because the wines have different compositions, they react differently with the same clarifying agent. Therefore, the efficacy of the fining agent will depend on the product used, the preparations, the method of addition, the dosage, $\mathrm{pH}$, metal content, temperature, dissolved $\mathrm{CO}_{2}$ level and previous treatments in wines.

According to [5], the possible traces of casein, isinglass and eggs (ovalbumin) in clarified wines presents a low

\footnotetext{
a e-mail: frespine@ucs.br.,fernanda. laren@ibravin. org.br

b e-mail: celso_blatt@agilent.com

c e-mail: mariana.baptistao@agilent.com
}

risk for consumers allergic to these proteins and labeling can generate a negative impact both for non- allergic consumers as well as for the allergic ones. According to this author, if a person allergic to albumin ingest a liter of wine, considering limit of detection of this protein, would be consuming less than $0.06 \mathrm{mg}$ of egg white.

Different analytical methods are proposed in the literature to quantify allergenic residues in wines based on immunoassay techniques and mass spectrometry [6-16].

According to [16], immunoassays have the advantage of being quick and simple to perform, however, they are not as accurate as mass spectrometric assays. ELISA tests have some disadvantages due to the presence of interfering compounds in the matrix [8], such as polyphenols in red wines, which interact with proteins and antibodies [6].

To avoid these problems, methods for the direct detection of food allergens by mass spectrometry (MS) were developed [14]. Due to the high sensitivity, precision and reproducibility, mass spectrometry allows the detection of traces of proteins and makes identification independent of the structure of allergens [17].

Thus, this study aims to determine the presence of residues of allergenic oenological coadjuvants in experimental wines treated with different concentrations of casein, albumin and lysozyme, by a triple quadrupole (QQQ) ESI-LCMS. 


\section{Material and methods}

\subsection{Reagents, standards, glassworks and materials}

All reagents used in this work were purchased from the brand Sigma-Aldrich, as well as the certified analytical standards for alpha-casein, beta-casein and ovalbumin. The analytical standard of lysozyme was purchased from Worthington Biochemical Corporation.

\subsection{Experimental wines}

The elaboration of experimental wines was carried out at the Laboratory of Oenologic Reference Evanir da Silva (LAREN) of the Secretariat of Agriculture, Livestock and Irrigation of the State of Rio Grande do Sul (SEAPI), linked to the Brazilian Wine Institute (IBRAVIN) located in Caxias do Sul, Rio Grande do Sul, Brazil.

\subsubsection{Red wine elaboration}

The microvinifications were performed in duplicates, in stainless steel tanks with a capacity of 10 liters. The grape samples $(115 \mathrm{~kg}$ ) of Merlot variety, from the city of Antônio Prado - RS - Brazil, were destemmed and crushed, totaling 14 tanks, containing approximately $8 \mathrm{~kg}$ of grapes each one. The grapes were microvinificated by the traditional process with maceration of the film. After destemming, sulfur dioxide was added to the must at a concentration of $40 \mathrm{mg} / \mathrm{L}$ and after 30 minutes Saccharomyces cerevisiae (Maurivin brand) yeast was added at a concentration of $300 \mathrm{mg} / \mathrm{L}$. The removal of the peels was determined by the relative density (approximately 1020), and the wine finished the fermentation in $4.5 \mathrm{~L}$ glass bottles, closed with Muller's valve. The wine undergoes spontaneous malolactic fermentation. After the end of the alcoholic and malolactic fermentation, the wines were transferred to another glass bottle and corrected to $40 \mathrm{mg} / \mathrm{L}$ of free sulfur dioxide for preservation. The tartaric stabilization was carried out at $0^{\circ} \mathrm{C}$ for 20 days and then a new transfer for the removal of bitartrate crystals. After, different concentrations of albumin $(30,150$ and $200 \mathrm{mg} / \mathrm{L})$ and potassium caseinate $(50,125$ and $250 \mathrm{mg} / \mathrm{L})$ of the brand AEB Improvement Through Biotechnology were added in the bottles. A week after, bentonite was added for the removal of the fining agents and the wines decanted during four days, followed by a new transfer to $750 \mathrm{ml}$ bottles (totaling 4 bottles per experiment), remaining stored in ideal conditions for subsequent analysis.

\subsubsection{White wine elaboration}

Chardonnay grape samples $(120 \mathrm{~kg})$ from the city of Antônio Prado were destemmed and crushed. The extraction of the must was carried out in press, not taking part of the peels in the fermentation. Microvinifications were performed in duplicates in 4.5 liter capacity glass bottles, totaling 14 bottles containing approximately $8.5 \mathrm{~kg}$ of must. Sulfur dioxide was added to the must at $40 \mathrm{mg} / \mathrm{L}$ and after 30 minutes the albumin and lysozyme (brand AEB Improvement Through Biotechnology) were added, at the concentrations of 200,400 and $600 \mathrm{mg} / \mathrm{L}$ and 200, 400 and $500 \mathrm{mg} / \mathrm{L}$, respectively. After an hour and
30 minutes, Saccharomyces cerevisiae (Maurivin brand) yeast was added at a concentration of $400 \mathrm{mg} / \mathrm{L}$. The wine finished the fermentation in $4.5 \mathrm{~L}$ bottles, closed with Muller valve. After the alcoholic fermentation, the wines were transferred and the free sulfur dioxide was corrected to $40 \mathrm{mg} / \mathrm{L}$. Subsequently, the bentonite was added for the removal of the fining agents and the tartaric stabilization (and decantation) was performed at $0{ }^{\circ} \mathrm{C}$ for 20 days. After, the wines were bottled in $750 \mathrm{~mL}$ bottles (totaling four bottles for each type of treatment), remaining stored in ideal conditions of temperature and humidity, for subsequent analysis.

\subsection{Analysis}

The analyses were performed according to the adaptation of the methods of [14] and [16]. The treatment of the wines prior to the analysis was done in the Laboratory of Oenologic Reference (Caxias do Sul - RS - Brazil), following the method of [14] with some adaptations and the analysis were performed in a triple quadrupole ESILCMS at Agilent Technologies laboratory, in Barueri São Paulo - Brazil.

\subsubsection{Treatment of samples}

Day 1: Proteins were recovered by the Potassium Dodecyl Sulfate (KDS) method [18], starting from $50 \mathrm{~mL}$ of wine. $10 \%$ SDS was added to the wine at a final concentration of $0.2 \%$. Samples were heated at $100{ }^{\circ} \mathrm{C}$ for 10 minutes. After cooling, $10 \mathrm{~mL}$ of $2 \mathrm{M} \mathrm{KCL}$ were added and the samples were gently mixed for 45 minutes at $4{ }^{\circ} \mathrm{C}$. Protein pellets were recovered by centrifugation at $4300 \mathrm{rpm}$ for 60 minutes at $4{ }^{\circ} \mathrm{C}$, the supernatant was discarded and the pellets were maintained in $1 \mathrm{~mL}$ of $20 \%$ trichloroacetic acid overnight.

Day 2: Samples were centrifuged at $4300 \mathrm{rpm}$ for $60 \mathrm{~min}$, the supernatants were discarded and, to further remove the SDS, the protein pellets were washed with cold acetone three times ( $5 \mathrm{~mL}$ of acetone each time). Samples were centrifuged at $4300 \mathrm{rpm}$ for $30 \mathrm{~min}$, supernatants were discarded and the protein pellets were let dry. Protein pellets were dissolved in $1 \mathrm{~mL}$ of $\mathrm{NH}_{4} \mathrm{HCO}_{3} 50 \mathrm{mM}$ containing $8 \mathrm{M}$ of urea. For reduction step, dithiotreitol (DTT) was added to a final concentration of $10 \mathrm{mM}$ and mixture was incubated at $37^{\circ} \mathrm{C}$ for an hour. For alkylation step, iodoacetamide (IAM) was added to a final concentration of $30 \mathrm{mM}$ and the mixture was left an hour at room temperature, in the dark. $1 \mu \mathrm{g}$ of sequencing grade modified trypsin was added after the dilution of the samples with $50 \mathrm{mM} \mathrm{NH} 4 \mathrm{HCO} 3$ to reach a final concentration of $0.4 \mathrm{M}$ of urea, and digestion was carried out overnight at $37^{\circ} \mathrm{C}$.

Day 3: The samples were desalted with $\mathrm{C} 18$ cartridges (Econo-Pac 10DG Columns, Bio-rad) and the extracted peptides were dissolved in $40 \mu \mathrm{L}$ of $10 \%$ formic acid to stop the digestion reaction before the analysis.

\subsubsection{Triple quadrupole ESI-LCMS parameters}

The analysis were performed in a 6400 Series Triple Quadrupole LCMS (Agilent Technologies) using a Jet Stream Electrospray Ionization (ESI) and the software Mass Hunter. LC separation was performed in a HPLC 1260 series using a $50 \mathrm{~mm} \times 2.1 \mathrm{~mm}, \quad \mathrm{C} 18$ 
Table 1. Precursor ion, product ion, collision energy and polarity for each peptide.

\begin{tabular}{|l|c|c|c|l|}
\hline Protein & $\begin{array}{c}\text { Precursor } \\
\text { ion }\end{array}$ & $\begin{array}{c}\text { Product } \\
\text { ion }\end{array}$ & $\begin{array}{c}\text { Collision } \\
\text { energy (v) }\end{array}$ & Polarity \\
\hline Alpha-casein & 692.9 & 295.1 & 26 & Positive \\
& & $267^{*}$ & 38 & \\
\hline Beta-casein & 1054.7 & $\begin{array}{c}1151.7^{*} \\
648.7\end{array}$ & 45 & Positive \\
\hline Albumin & 635.7 & 235 & 42 & Positive \\
& & $207^{*}$ & 50 & \\
\hline \multirow{2}{*}{ Lysozyme } & 715 & 804.6 & 30 & Positive \\
& & $249.1^{*}$ & 30 & \\
\hline
\end{tabular}

* Most abundant.

Poroshell 1120 column, thermostated at $45^{\circ} \mathrm{C}$ and a flow rate of $0.400 \mathrm{~mL} / \mathrm{min}$. Water/formic acid $0.1 \%$ and acetonitrile/formic acid $0.1 \%$ were used as eluents $\mathrm{A}$ and $\mathrm{B}$, respectively. The chromatographic separation was achieved under the following optimized gradient: solvent B was initially set at $5 \%$ for $1 \mathrm{~min}$, delivered by a linear gradient from 5\% to $10 \%$ in $5 \mathrm{~min}$, and then $3 \mathrm{~min}$ of rebalance for the next sample injection. Each sample was loaded $10 \mu \mathrm{L}$. Mass spectrometric conditions were set as follows: electrospray voltage $4 \mathrm{KV}$; gas temperature of $300{ }^{\circ} \mathrm{C}$, gas flow $9 \mathrm{~L} / \mathrm{min}$, sheath gas heater and sheath gas flow set to 250 and 11 arbitrary units. The system was operated in positive ion mode. All analysis were performed in triplicates.

\section{Results and discussion}

Before the analysis of the wines, the conditions of the method were optimized and the precursor ions and their respective products were investigated. Both full scan and multiple reaction monitoring acquisition (MRM) modes were performed. Most abundant ions of each protein were selected as protein markers to investigate the presence of the protein residues.

For lysozyme, the precursor ion found was the same used in the study of [16], as well as for alpha-casein, the same precursor ion as the study of [10]. For the other proteins (beta-casein and albumin), the ions found in this research are distinct from those reported in some studies $[14,16]$. The precursor ion and the product ion MRM transition monitored for each peptide are reported in Table 1.

The detection (LOD) and quantification (LOQ) limits were calculated on blank and on wine and were expressed as the concentration of the analyte giving a signal that is $3 \mathrm{~s}$ and 10 s above the mean blank signal, respectively, where is the standard deviation of the blank signal obtained from independent blank measurements.

Regarding the limits of detection and quantification, satisfactory values were found when compared with other studies that presented values between $0.4-50 \mathrm{mg} / \mathrm{L}$ $[10,19]$, except for the beta-casein that the LOQ was considered higher than expected. As expected, differences were observed in limits calculated on the blank matrix and the wine matrix. To assess recovery, a Merlot wine and a Chardonnay wines, without any protein treatment, were fortified with alpha and beta-casein, albumin and lysozyme
Table 2. Proteins curve correlations, LOD and LOQ.

\begin{tabular}{|c|c|c|c|c|c|}
\hline Protein & $\mathbf{R}^{\mathbf{2}}$ & \multicolumn{2}{|c|}{ LOD (mg/L) } & \multicolumn{2}{c|}{ LOQ (mg/L) } \\
\hline & & Blank & Wine & Blank & Wine \\
\hline Alpha-casein & 0.9901 & 0.04 & 0.07 & 0.12 & 0.24 \\
\hline Beta-casein & 0.9780 & 0.16 & 0.22 & 0.54 & 0.75 \\
\hline Albumin & 0.9976 & $6.10^{-3}$ & $7.10^{-4}$ & 0.02 & $2.10^{-3}$ \\
\hline Lysozyme & 0.9999 & 0.02 & 0.01 & 0.07 & 0.04 \\
\hline
\end{tabular}

Table 3. Recovery of proteins in wines.

\begin{tabular}{|c|c|c|}
\hline Protein & $\begin{array}{c}\text { Concentration } \\
\text { added }(\mathbf{m g} / \mathbf{L})\end{array}$ & $\begin{array}{c}\text { Average Recovery } \\
(\boldsymbol{\%})\end{array}$ \\
\hline Alpha-casein & 5.00 & 167 \\
\hline Beta-casein & 5.00 & 114 \\
\hline Albumin & 0.65 & 63 \\
\hline Lysozyme & 5.00 & 158 \\
\hline
\end{tabular}

before sample extractions and measurements were carried out by monitoring the most abundant transition for the peptide (Table 3 ).

A peak displacement was observed when addition tests were performed on wines, when comparing with the standards retention times. This displacement was attributed to the possible existence of SDS residues in the samples. As cited by [20], SDS dissolves proteins and prevents interactions (e.g., with phenols) that could occur during protein concentration. The addition of potassium ions induces the protein-detergent insolubilization and allows their recovery. KDS method has been proven useful for protein recovery from fermented beverages. Detergent addition, such as urea or SDS might help protein recovery, but chaotropic agents persist in the samples and could affect further analyses. The SDS could co-elute with the analyte of interest, potentially causing ion suppression. Therefore, calibration curves should be performed in the matrix.

Finally, applying the method to the experimental wines elaborated in this work, non-residues of alpha-casein, betacasein, albumin and lysozyme were identified. The results of this study are in accordance with the results obtained by [13] that analyzed, by ELISA test, experimental wines elaborated with the addition of $200-500 \mathrm{mg} / \mathrm{L}$ of caseinate and did not detect the presence of allergenic residues in the experimental wines.

\section{Conclusion}

Non-residues of the proteins were identified in the experimental wines treated with the different amounts of potassium caseinate, albumin and lysozyme, analyzed in this study. These results provide an evidence of the absence of residues of potassium caseinate, albumin and lysozyme in the concentrations tested in the wines if good treatment practices are followed. As perspectives of this work, tests will be carried out in the preparation of the samples to optimize the recovery of the proteins.

This study was part of an OIV Grant Research, therefore the authors thanks the OIV for supporting and funding this study. Also, the Brazilian Wine Institute, the Secretariat of Agriculture of the State of Rio Grande do Sul and the Coordination of 
Improvement Higher Level Personnel (CAPES) for their financial support. To the University of Caxias do Sul and to the company Agilent Technologies.

\section{References}

[1] Regulation (EU) No 1308/2013 of the European Parliament and of the Council of 17 December 2013 establishing a common organization of the markets in agricultural products and repealing Council Regulations (EEC) N.922/72 (EEC) N. 234/79 (EC) N. 1037/2001 and (EC) No 1234/2007

[2] OIV-COMEX 502-2012 Revision of the limit of detection and limit of quantification related to potentially allergenic residues of fining agent proteins in wine

[3] Commission Implementing Regulation (EU) No $579 / 2012$ of 29 June 2012 amending Regulation (EC) No 607/2009 laying down certain detailed rules for the implementation of Council Regulation (EC) No 479/2008 as regards protected designations of origin and geographical indications, traditional terms, labelling and presentation of certain wine sector products

[4] OIV/OENO 520/2014. Code of good fining practices for wine to be applied in the use of proteinaceous wine fining agents with allergenic potential (casein and egg white)

[5] E. Vassilopoulou, A. Karathanos, G. Siragakis, S. Giavi, A. Sinaniotis, N. Douladiris, M. FernandezRivas, M. Clausen, N.G. Papadopoulos, Clin. Transl. Allergy. 1, 10 (2011)

[6] P. Weber, H. Steinhart, A. Paschke, J. Agric. Food Chem. 55, 3127 (2007)
[7] J.M. Rolland, E. Apostolou, M.P. De Leon, C.S. Stockley, R.E. O'Hehir, J. Agric. Food Chem. 56, 349 (2008)

[8] P. Weber, H. Steinhart, A. Paschke, J. Agric. Food Chem. 57, 8399 (2009)

[9] A. D'Amato, A.V. Kravchuk, A. Bachi, P.G. Righetti, J. Proteomics 73, 2370 (2010)

[10] L. Monaci, I. Losito, F. Palmisano, A. Visconti, J. Chromatogr. A 1217, 4300 (2010)

[11] M. Lacorn, C. Gosswein, U. Immer, Am. J. Enol. Vitic. 62, 382 (2011)

[12] B. Simonato, F. Mainente, S. Tolin, G. Pasini, J. Agric. Food Chem. 59, 3101 (2011)

[13] P. Restani, F. Uberi, R. Danzi, C. Ballabio, F. Pavanello, C. Tarantino, Food Chem. 134, 1438 (2012)

[14] S. Tolin, G. Pasini, B. Simonato, F. Mainente, G. Arrigoni, Food Control 28, 321 (2012)

[15] L. Monaci, I. Losito, E. De Angelis, R. Pilolli, A. Visconti, Rapid Commun. Mass Spectrom. 27, 2009 (2013)

[16] M. Mattarozzi, M. Milioli, C. Bignardi, L. Elviri, C. Corradini, M. Careri, Food Control 38, 82 (2014)

[17] S. Kirschner, B. Belloni, C. Kugler, J. Ring, K. Brockow, J. Investig. Allergol. Clin. Immunol. 19, 210 (2009)

[18] S. Vincenzi, S. Mosconi, G. Zoccatelli, C. Dalla Pellegrina, G. Veneri, R. Chignola, A. Peruffo, A. Curioni, C. Rizzi, Am. J. Enol. Vitic. 56, 182 (2005)

[19] L. Monaci, A. Visconti, Trends Analyt. Chem. 28, 581 (2009)

[20] F. Mainente, C. Rizzi, G. Zoccatelli, R. Chignola, B. Simonato, G. Pasini, Eur. Food Res. Technol. 242, 1803 (2016) 